\title{
ANÁLISE DAS MANIFESTAÇÕES PATOLÓGICAS EM LAJE DE CONCRETO ARMADO DESTINADO À CIRCULAÇÃO DE VEÍCULOS- GARAGEM- ESTUDO DE CASO EDIFICAÇÃO COMERCIAL LOCALIZADA EM PORTO ALEGRE
}

\author{
JOSIELE. DE LORENZI F. DE OLIVEIRA \\ Arquiteta e urbanista, Pós graduação em \\ Patologia das Construções \\ UNISINOS - Univ. do Vale do Rio dos Sinos \\ Rio Grande do Sul; Brasil \\ josidelorenzi@terra.com.br
}

\section{ROBERTO. CHRIST}

Pós graduação - Doutorado em Engenharia Civil

itt Performance UNISINOS- Univ.Vale do Rio dos Sinos

Rio Grande do Sul; Brasil

rchrist@unisinos.br

\author{
BRUNA. QUEIROZ DO PRADO \\ Arquiteta e urbanista, Pós graduação em \\ Produção Civil \\ PUCRS - Pontifícia Universidade Católica do \\ Rio Grande do Sul; Brasil \\ brunaqueiroz@gmail.com
}

\section{FERNANDA. PACHECO}

Pós graduação - Doutorado em Engenharia Civil

itt Performance UNISINOS-Univ.Vale do Rio dos Sinos

Rio Grande do Sul; Brasil

fernandapache@unisinos.br

\section{RESUMO}

O objetivo deste artigo é de identificar e diagnosticar as manifestações patológicas evidenciadas em uma laje de concreto armado de um edifício garagem na cidade de Porto Alegre/RS. O estudo foi realizado em uma laje com área de $502,45 \mathrm{~m}^{2}$, em edifício comercial com 4 anos de uso. Após a identificação das manifestações patológicas através da inspeção visual, mapeou-se as fissuras com o intuito de identificar as configurações, foi realizado ensaios não destrutivos, como determinação das espessuras e comprimentos das fissuras com o auxílio do fissurômetro e trena. Supostamente a principal causa evidenciada para a ocorrência das fissuras na laje em estudo foi a retração hidráulica. Porém também possuem fissuras causadas por ineficiência ou falta de armaduras negativas, algumas fissuras passam $100 \%$ da espessura da laje desencadeando o processo de corrosão das armaduras. Recomenda-se uma análise aprofundada do projeto estrutural, ensaios e o monitoramento das fissuras, para as soluções dos reparos ideais.

Palavras-chave: anomalias em lajes, fissuras, trincas, concreto ,estruturas, armaduras..

\section{ABSTRACT}

The aim of this article is to identify and diagnose the pathological manifestations evidenced in a reinforced concrete slab of the garage building in Porto Alegre / RS. The study was carried out in a slab with an area of $502.45 \mathrm{~m}^{2}$, in a commercial building with 4 years of use. After identifying the pathological manifestations by visual inspection, the cracks were mapped in order to identify the configurations, non-destructive tests were performed, such as the determination of the thickness and length of the cracks with the aid of the fissurometer and tape measure. The main cause evidenced for the occurrence of cracks in the slab under study was the hydraulic retraction. But they also have cracks caused by inefficiency or lack of negative reinforcement, some cracks pass $100 \%$ of the slab thickness triggering the reinforcement corrosion process. An in-depth analysis of structural design, testing and crack monitoring is recommended for optimal repair solutions.

Keywords: anomalies ins slabs, cracking, concrete, reinforcement.

\section{INTRODUÇÃO}

A evolução das tecnologias dos materiais e das técnicas de execução, requer projetos bem detalhados, com materiais especificados e de boa qualidade, visando amenizar as manifestações patológicas (THOMAZ,1989). A durabilidade das estruturas de concreto abrange vários fatores, levando em consideração os materiais utilizados na mistura (agregado, cimento, aço, etc) como a relação a/c, uso de aditivos e adições e sua execução como adensamento, cura e remoção das formas. Cabe citar que a durabilidade é a capacidade da estrutura em resisitir a qualquer processo de deterioração relacionado a agressividade do entorno (CHODOUNSKY;VIECILI,2007; ZORZAN;OLIVEIRA; MEDEIROS; SOUZA,2016). 
O presente artigo teve o intuito de estudar o caso das manifestações patológicas da laje de concreto no térreo de um empreendimento comercial, localizado em Porto Alegre, com área de $502,45 \mathrm{~m}^{2}$, com dimensões de 39,50m x 11,35m. Seu uso é de estacionamento rotativo, este tipo de piso deve apresentar propriedades e requesitos de desempenho de durabilidade, dureza e resistência, inclusive a de abrasão e a impactos, devido ao fato da superfície ser submetida ao tráfego de veículos (CHODOUNSKY;VIECILI,2007;OLIVEIRA;SANTOS,2016).

A ênfase do artigo é dada ao mecanismos de formação das fissuras, levando em conta que as fissuras são provocadas por tensões de sobrecarga, deformabilidade excessiva, como retração hidráulica e de secagem (THOMAZ,1989), não tão menos importante as juntas de dilatação nos pisos de concreto, no qual muitas fissuras estão relacionadas a falha de execução (CHODOUNSKY;VIECILI,2007).

As manifestações patológicas presentes na pesquisa foram coletadas através de inspeção visual, os dados identificados, fotografados e mapeados. Avaliou-se o uso do edifício de 4 anos de uso, verificando as aberturas de fissura, com medição do cobrimento e a presença de armaduras.

\section{CONCEITOS BÁSICOS}

O sistema estrutural é composto por vigas, lajes e pilares, distribuindo os esforços do sistema até as fundações (CAPORRINO,2018). As estruturas de concreto armado, apresentam deformações que não afetam o comportamento dos componentes da estrutura, desde que sejam calculadas evitando as manifestações patológicas com a teoria da elasticidade e as técnicas desenvolvidas regulamentadas (THOMAZ,1989). As estruturas de concreto podem se considerar de vida útil longa, desde que os projetos sejam bem elaborados, bem executados com seus devidos critérios e as manutenções preventivas e corretivas necessárias para atingir a sua vida útil projetada (SANTOS,2014).

\subsection{Aspectos Teóricos Lajes de Concreto Armado}

O concreto possui mais resistência à compressão do que à tração (MEHTA;MONTEIRO, 2008), e assim, na zona tracionada percebe-se o surgimento de fissuras, conforme figura 1 (BOTELHO;MARCHETTI,2004; TRINDADE,2015).

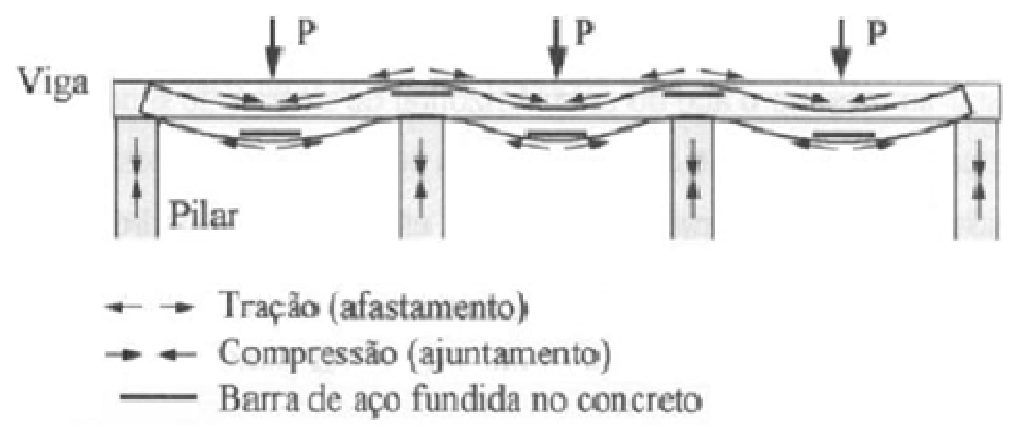

Figura 1: Zonas de tração e compressão (BOTELHO,1996)

Com a necessidade de atingir grandes vãos foi adicionado os aços na zona tracionada, resultando num material resistente à compressão e à tração, na figura 2 tem-se as zonas suscetíveis aos esforços e a linha neutra da estrutura (BOTELHO; MARCHETTI,2004; TRINDADE,2015).
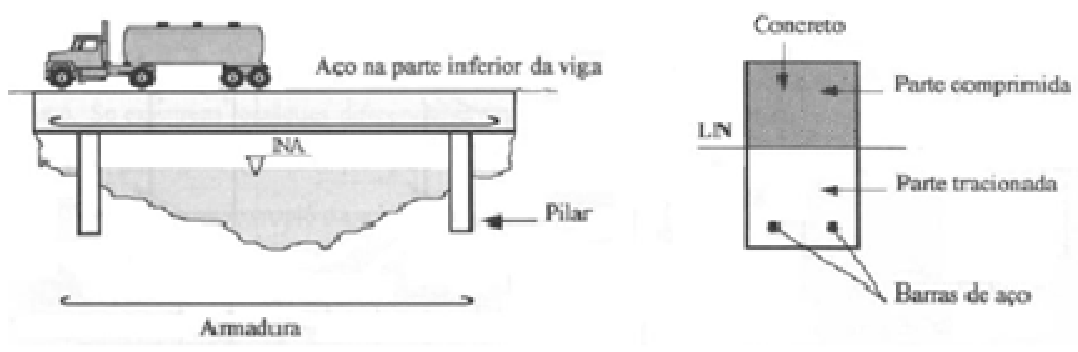

Figura 2: Zonas de tração, compressão e a linha neutra da estrutura (BOTELHO,1996) 


\subsection{Estrutura dos pisos de concreto}

Os pisos de concreto podem ser apoiados no solo ou em forma de laje. Marcel e Fábio classificam as finalidades básicas para os pisos de concreto (CHODOUNSKY;VIECILI,2007):

-Resistir e distribuir ao subleito os esforços verticais produzidos pelo carregamento; -Proporcionar perfeito rolamento, quanto ao conforto, limpeza e segurança, das cargas móveis (automóveis), possuindo textura superficial a adequada à futura utilização;

- Resistir aos esforços mecânicos (flexão, compressão, impacto e abrasão) e a ataques químicos ou biológicos (ácidos, bases, monóxido de carbono, sulfatos, bactérias, etc.)

Nos pisos de concreto, como já citado é imprescindível durabilidade e dureza, com planicidade adequada para a utilização, garantindo a limpeza e escoamento de líquidos, além de resistência a abrasão e ação de substâncias químicas. Os pisos de concreto podem relativamente estarem livres de fissuras, desde que estejam em conformidade com a grade de referência (CHODOUNSKY;VIECILI,2007;OLIVEIRA;SANTOS,2016).

\section{MANIFESTAÇÕES PATOLÓGICAS E SUAS CAUSAS}

Os danos patológicos em edificações podem ter origem endógena, exógena, funcionais e naturais, podendo ocorrer grandes e pequenos danos que reduzem a durabilidade e resistência mecânica (SANTOS,2014;TRINDADE,2015). Em relação às fissuras, essas podem surgir desde a elaboração do projeto, sem conhecimento das movimentações dos materiais e os componentes das edificações. A execução e a cura dos elementos são fundamentais para reduzir a ocorrência das fissuras (CHODOUNSKY;VIECILI,2007;SOUZA,2017;SOUZA;RIPPER,1998;THOMAZ,1989; TRINDADE,2015). Conforme João Carlos (SOUZA;RIPPER,1998) são classificadas conforme a espessura das fendas.

- Fissuras são de aberturas com menos de $0,5 \mathrm{~mm}$, são estreitas e alongadas, de menor gravidade.

- Trincas são de aberturas de 0,5 a $1,5 \mathrm{~mm}$, são mais acentuadas e profundas, podendo ocorrer ruptura do elemento estrutural.

- Rachaduras aberturas superior a 1,5mm, profundas e bem destacadas, permitindo o ar e água, causando corrosão das armaduras e reações químicas (SOUZA,2017).

As fissuras são provocadas por vários fatores, onde foi abordado as principais fissuras em laje de concreto armado, relacionado ao case estudado.

\subsection{Fissuras por retração}

\subsubsection{Retração Plástica}

A superfície exposta/volume, no seu estado fresco diante de uma secagem rápida do concreto, devido aos fatores de evaporação e exsudação da água, relacionados a fatores como umidade relativa do ar, velocidade do vento, relação água $\mathrm{x}$ cimento, temperatura do ar e do cimento, originando as fissuras, quando o concreto fresco na superfície externa atingi a sua taxa de evaporação da umidade maior que a de exsudação ele se retrai, quando atingi a retração diferente ao interno induzindo a fissuração de devido à baixa resistência na fase de enrijecimento (CHODOUNSKY;VIECILI,2007; OLIVEIRA;SANTOS, 2016).

Tais fissuras de retração são tipicamente paralelas entre si, com espaçamentos entre 0,2 e 1,0m e geralmente entre 25 e $75 \mathrm{~mm}$ de profundidades e grandes aberturas.

Com medidas de controle da taxa de evaporação da água do concreto, como resfriamento, alteração de horário da concretagem, controle dos ventos, borrifamento ou aspersão de neblina de água, adição de agentes redutores de evaporação são medidas eficazes para a redução das fissuras.

\subsubsection{Retração hidráulica ou secagem}

Ocorre na mesma maneira que a retração plástica, porém podem surgir precocemente logo após a pega do concreto ou após a execução de 90 dias ou mais (CHODOUNSKY;VIECILI,2007), com a secagem do concreto o aumento do teor 
de umidade ocorre a expansão do material enquanto a contração pela diminuição da umidade, podendo resultar em fissuras (OLIVEIRA;SANTOS,2016;THOMAZ,1989).

A limitação desse encurtamento devido a existência da armadura, induz ao aparecimento de elevadas tensões de tração, dos valores de deformação e do coeficiente de fluência do concreto podendo romper o concreto (69.

As fissuras normalmente ocorrem na transversal do sentido da placa conforme figura 3, quando ocorrem precocemente indicam falhas por atraso do corte das juntas de retração ou cura ineficiente. Já quando ocorrem mais tarde indicam deficiência no projeto ou na execução, outros fatores que contribuem as juntas de dilatação não estarem no local adequado ou falta, armadura insuficiente ou mal posicionada, concretos com elevada retração (CHODOUNSKY;VIECILI,2007).

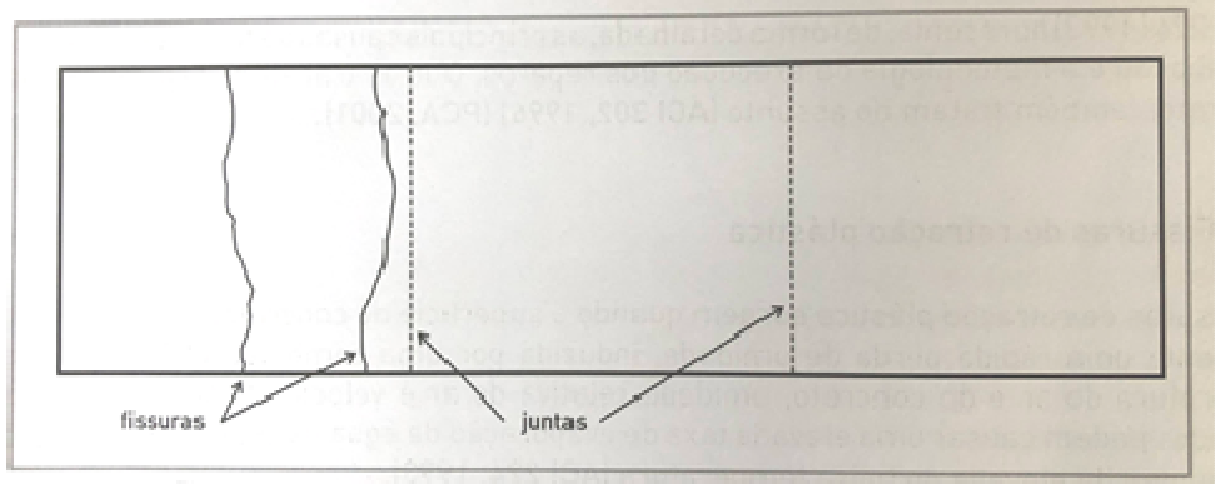

Figura 3: Exemplos de fissura de retração hidráulica (CHODOUNSKY;VIECILI,2007)

\subsubsection{Microfissuras tipo pé de galinha}

Geralmente são pouco visíveis sendo mais notadas após sua molhagem, por apresentarem características de pequena profundidade inferiores a $3 \mathrm{~mm}$, superficiais e de espaçamento em torno de $50 \mathrm{~mm}$ entre si. Os fatores que contribuem com essas microfissuras são agregados com excesso de impurezas e elevado teor de finos, má execução da cura e a exposição a baixa umidade relativa do ar e/ou elevada temperatura do ar e exposição ao vento e sol diretos (CHODOUNSKY;VIECILI,2007;OLIVEIRA;SANTOS,2016).

\subsubsection{Retração Química}

É a redução de volume desde a iniciação da hidratação que ocorre pela a reação química entre o cimento e a água, devido elevadas forças interiores de coesão, a água combinada quimicamente (THOMAZ,1989).

\subsection{Fissuras típicas em laje de concreto armado devido à sobrecarga}

\subsubsection{Flexão de lajes}

A característica das fissuram variam conforme o contorno da laje (livre ou engastada), tipo de armação, a relação comprimento e largura (THOMAZ,1989). Na figura 4 representam-se fissuras de sobrecarga excessiva, por insuficiência da espessura do concreto ou armaduras. 


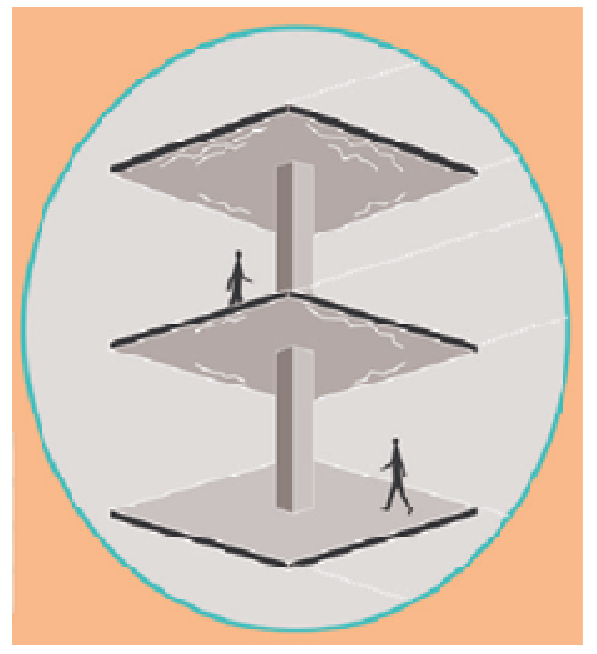

Figura 4 : Fissuras de sobrecarga excessiva (SOUZA,2017)

A característica típica do fissuramento na ruptura de uma laje simplesmente apoiada, armada em cruz e uniformemente com as cargas distribuídas, representada na figura 5 (THOMAZ,1989). Na figura 6 quando possui insuficiência nas armaduras positivas e ancoragem na laje de concreto armado (SOUZA,2017).

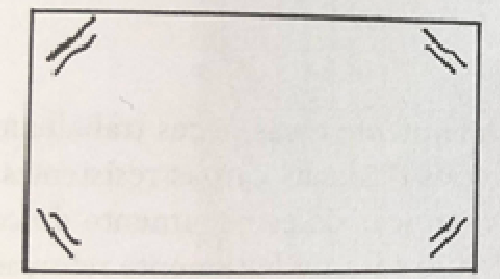

Foce Superior

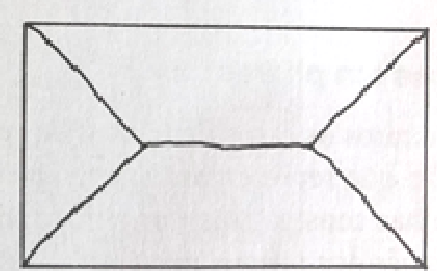

Foce Inferior

Figura 5 : Fissura de lajes simplesmente apoiadas (THOMAZ,1989)

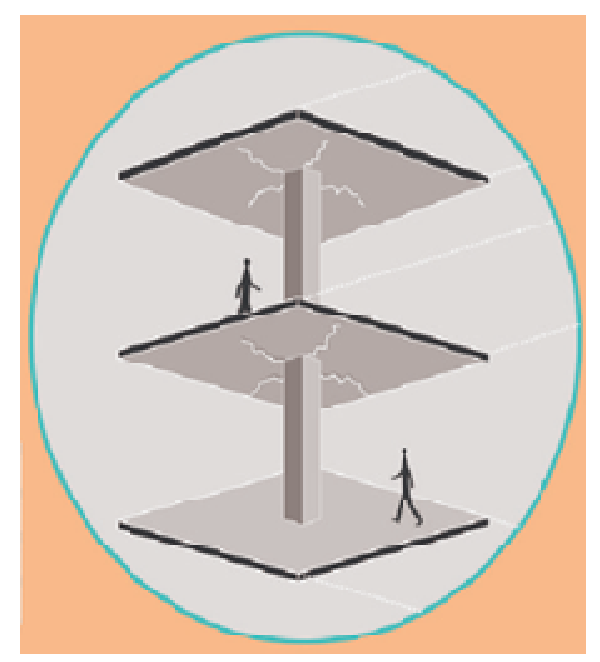

Figura 6 : Fissuras por insuficiência de armadura positiva (SOUZA,2017)

Conforme Thomaz, outro tipo de fissuras em lajes continuas projetadas simplesmente apoiadas, surgem na face superior da laje, acompanhando aproximadamente o seu contorno, devido à ausência de armadura negativa conforme a figura 7 (THOMAZ,1989). 


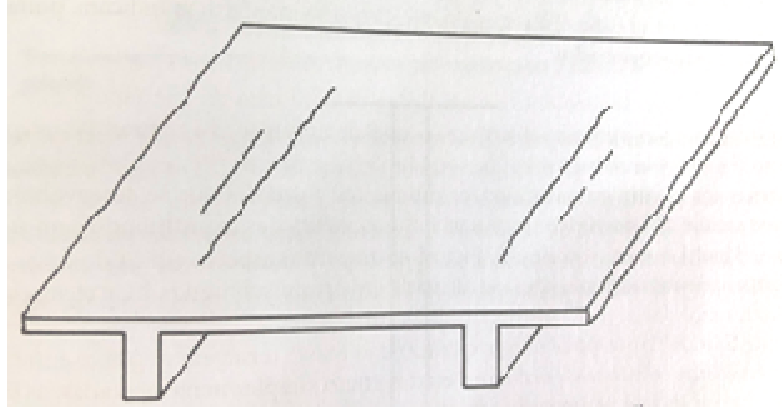

Figura 7 : Fissuras na ausência de armadura negativa (THOMAZ,1989)

\subsubsection{Torção de lajes}

As fissuras apresentam-se inclinadas em relação as bordas da laje, conforme figura 8, elas podem ocorrem por deformabilidade da estrutura da laje ou por recalques diferenciados nas fundações (THOMAZ,1989).

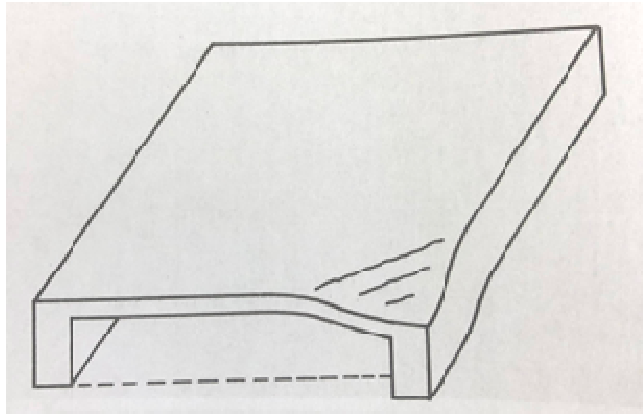

Figura 8 : Fissuras inclinadas devido a torção da laje (THOMAZ,1989)

\subsection{Manifestações patológicas pela ineficiência das juntas de dilatação}

Na NBR 6118:2014 (ABNT,2014) tem-se que as juntas de dilatação devem ser previstas pelo menos a cada 15m, sendo necessário afastamento maior levar em consideração nos cálculos os efeitos da retração térmica do concreto, da retração hidráulica e das reduções de temperatura, caso não ocorra a execução das juntas na localização correta, fissura no local que ocorre os esforços, pois sua função é dividir (limitar) as dimensões das placas de concreto (XEREZ NETO,2013). Essas fissuras denominadas fissuras de dilatação, absorvem essas tensões permitindo a movimentação do piso e a descontinuidade do concreto (CHODOUNSKY;VIECILI,2007).

Para execução correta Xerez Neto, explica que após a concretagem, as juntas são serradas com espessura máxima de $6 \mathrm{~mm}$ e profundidade máxima de $1 / 3$ a $1 / 4$ em relação à altura da placa, sob a junta as placas de concreto se mantem unidas. A junta executada somente na superfície e serradas cerca de 14 horas a 18 horas após lançamento. As juntas de dilatação não devem ter presença de quaisquer continuidades ou materiais rígidos no interior ou parte externa (cobrimento) (XEREZ NETO,2013).

É definido como quebra das bordas das juntas, as juntas são pouco resistentes a impactos, podem ocorrer por diferentes fatores. Existem outras manifestações patológicas nas lajes de concreto, tais como: desgaste por abrasão, delaminação, empenamento e borrachudo (CHODOUNSKY;VIECILI,2007;OLIVEIRA;SANTOS,2016).

\section{MÉTODOS}

\subsection{Levantamento de dados da edificação}

Foi visado a análise de uma laje de concreto armado especifica para o estudo deste artigo, localizada no andar térreo de uma edificação de 16 pavimentos sendo 1 subsolo. A área em estudo contem parte das vagas de garagem do edifício de fins comerciais com uma área privada de $502,45 \mathrm{~m}^{2}$ e dimensões de $39,50 \mathrm{~m} \times 11,35 \mathrm{~m}$, onde funciona um estacionamento rotativo. A edificação possui mais 4 andares de estacionamento e o restante de salas comerciais. 


\subsection{Identificação visual, levantamento métrico e fotográfico}

A principal manifestação patológica é o aparecimento de fissuras e trincas em toda a área de piso. Tais danos foram mapeados in loco através de medições e desenhos e evidenciados através de giz para identificação de formato e de fácil visualização fotográfica.

\subsection{Medições e detecção de armaduras.}

Foi efetuada medições das aberturas de fissuras e trincas com uso de fissurômetro para identificação e classificação das mesmas e assinaladas em desenho de mapeamento e com uso de detector com aparelho D-TECT 150 Profissional da marca Bosch foram localizadas as armaduras.

\section{RESULTADOS}

\subsection{Inspeção visual}

Conduziu-se levantamento in loco da parte analisada assim detalhadamente identificadas as manifestações patológicas observadas foram corrosão de armaduras, armaduras expostas e a principal, muitas fissuras e trincas em todo o piso da garagem, como apresentados nas figuras 09 até 16.

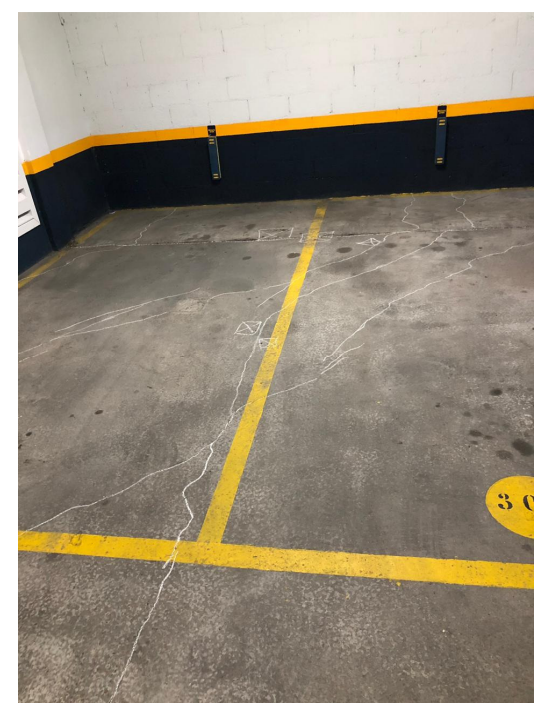

Figura 9 : $\operatorname{Em~} 45^{\circ}(302$ e 303$)$

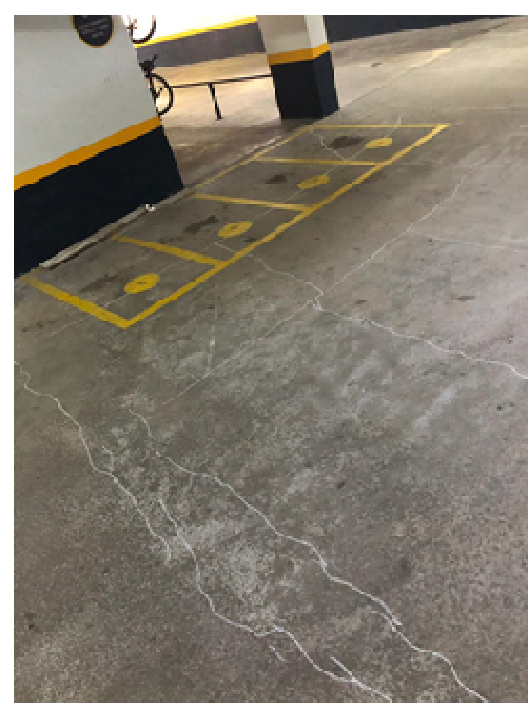

Figura 12 : Box $8,9,10$ e 11

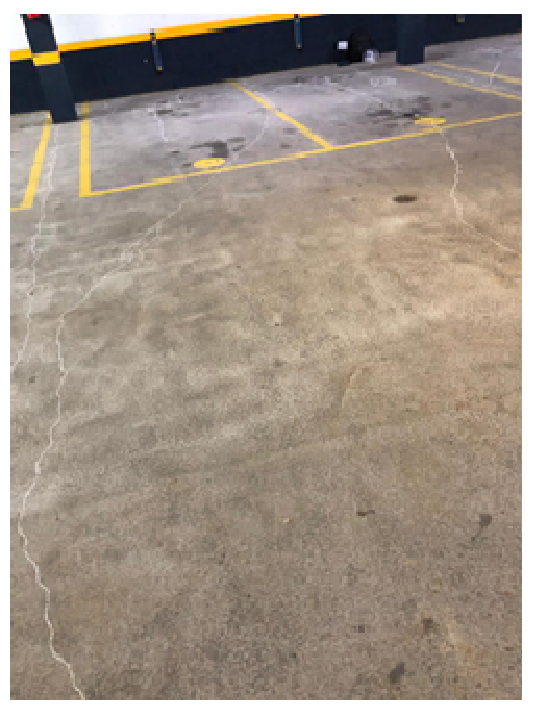

Figura 10 : Box 300 e 301

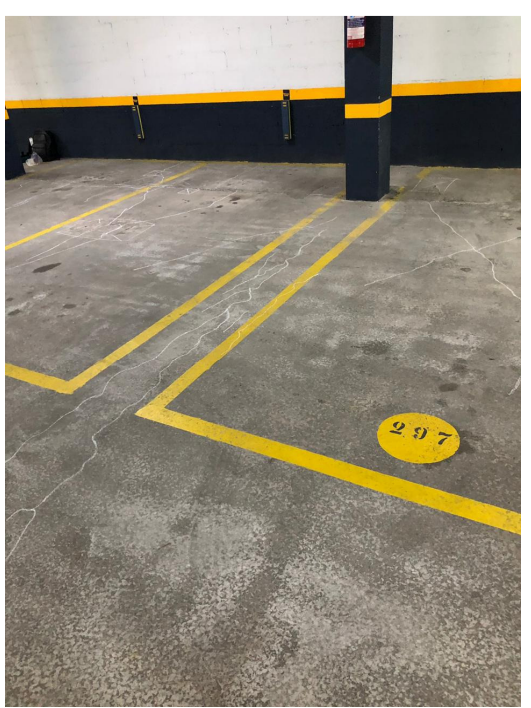

Figura 13 : Box 297 e 298

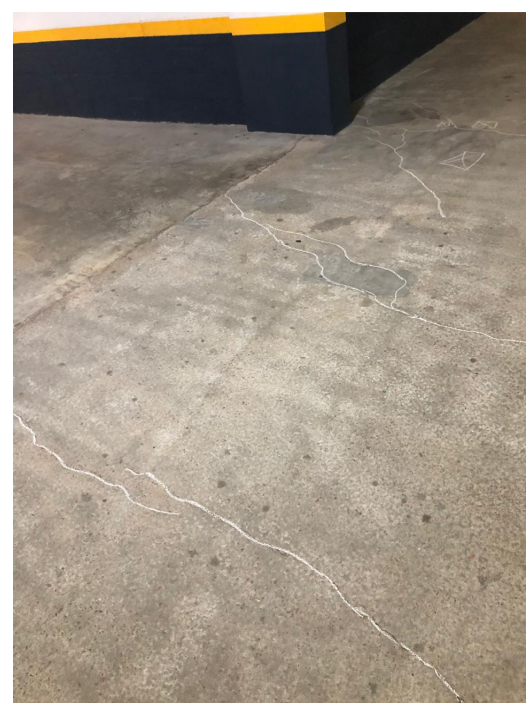

Figura 11 : Pilar acesso de veículos

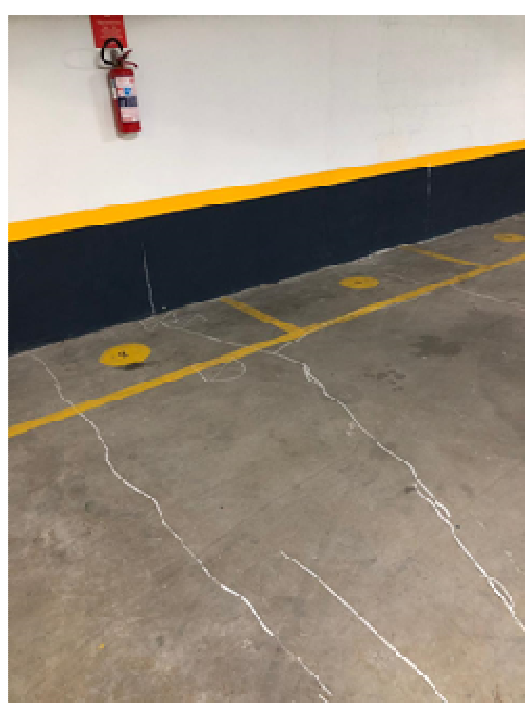

Figura 12 : Box 02 e 03 
Também verificou-se que em $247,11 \mathrm{~m}^{2}$ de piso, foi executado um novo piso de concreto, do box 296 até 303 , conforme figura 15 identificou-se falhas em alguns pilares e diferença de altura e aspecto do piso polido e alisado, o reparo foi realizado ainda na fase da construção conforme declaração do proprietário, sendo antes da utilização do edifício, não identificou-se a possível causa, mas voltou a apresentar as fissuras.
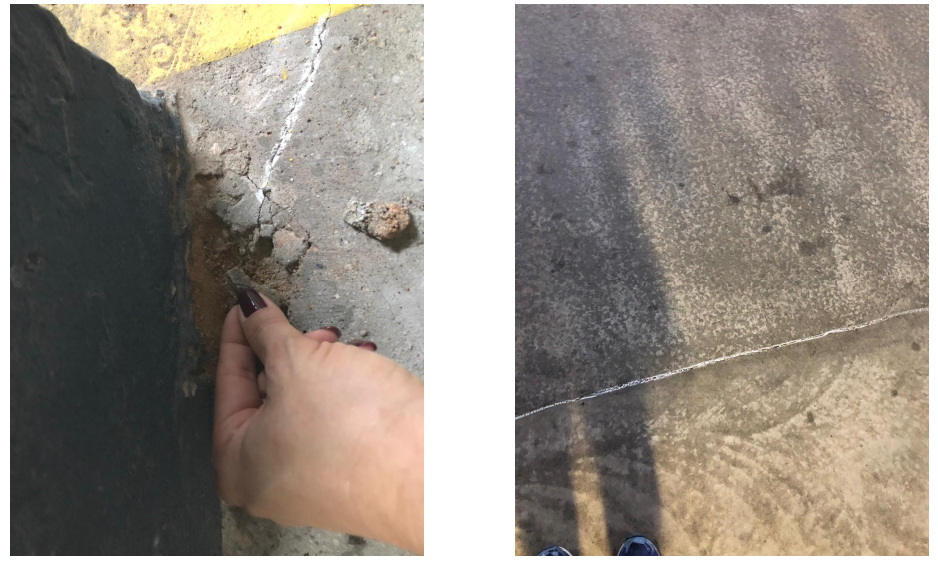

Figura 15: Falha do novo piso de concreto

\subsection{Mapeamento fissuras, trincas e rachaduras}

Após o levantamento fotográfico com mais de 3 centenas de fotos, conforme figura 16 foi desenhando um mapeamento das fissuras e trincas, identificando suas configurações na laje para a verificação do real estado de cada pano da laje, analisando-se individualmente e como um todo esse elemento estrutural. Foi identificado em 2 pontos fissuras com continuidade na parede. Na figura 16 as fissuras na cor magenta representadas, sugerem ser fissuras de dilatação, passam $100 \%$ da espessura da laje, ou seja, aparecem nas duas faces da laje.

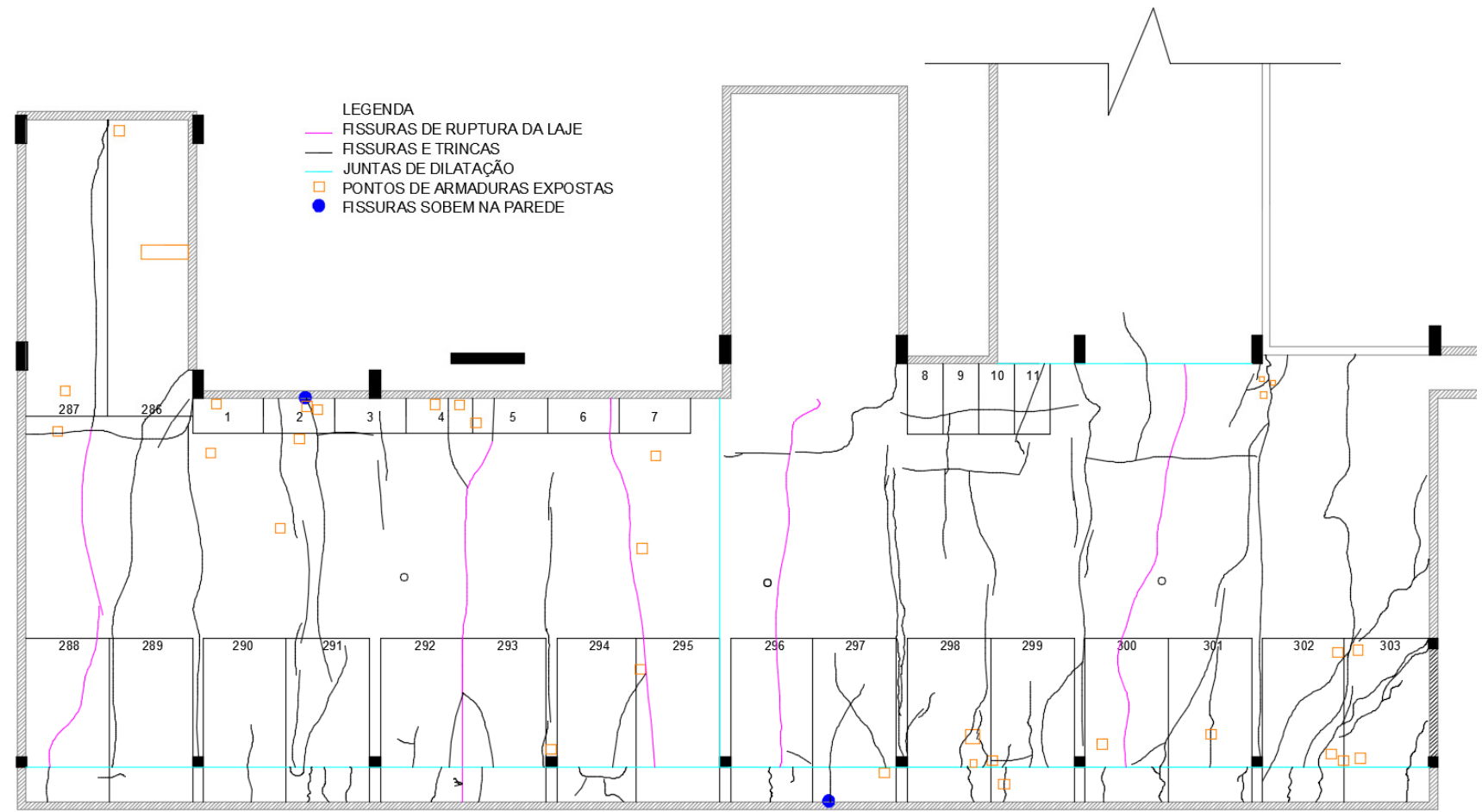

Figura 16 : Mapeamento das fissuras 


\subsection{Armadura}

\subsubsection{Corrosão das armaduras}

Na face superior das lajes não foram identificados pontos de corrosão, mas conforme a figura 17 na face inferior das lajes em algumas apresentam o mapeamento das armaduras já em processo de corrosão, sem o cobrimento necessário das armaduras.
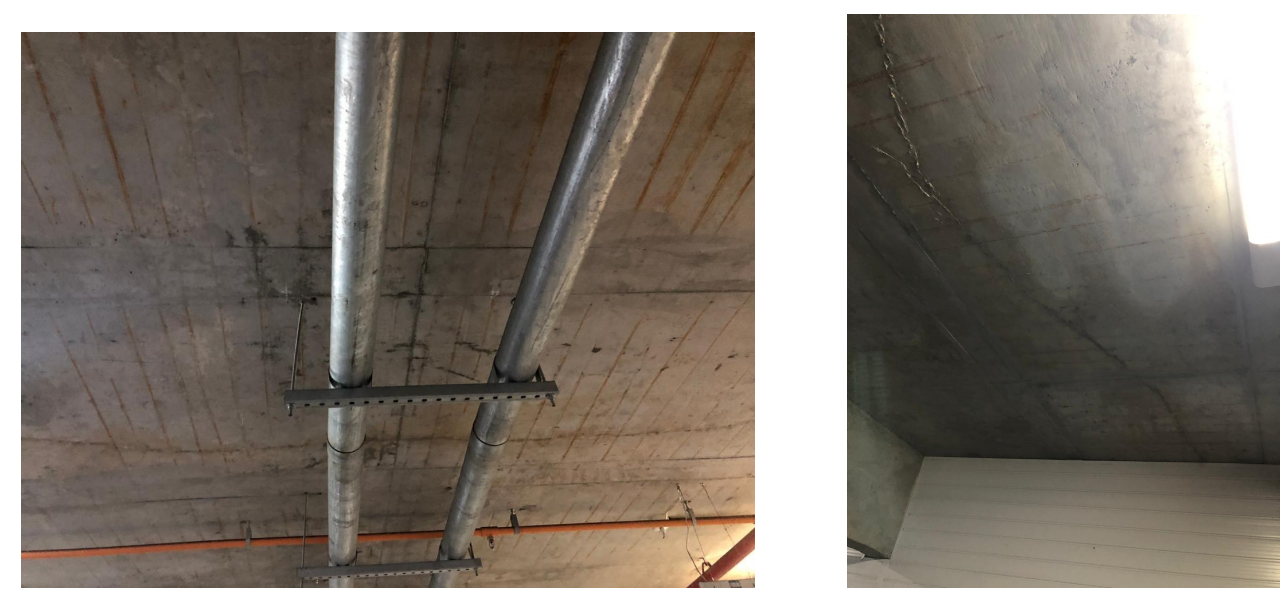

Figura 13 e 18 : Armadura positiva em processo de corrosão

Nas figura 17 e 18 observa-se fissuras de dilatação em $100 \%$ da altura da estrutura da laje, com manchas de corrosão e manchas brancas ou estalactites, no mesmo sentido das vigas e sentido contrário das armaduras positivas. Além das corrosões das armaduras, na face superior vários pontos de armaduras expostas e armaduras serradas, conforme figura 19 e 20.
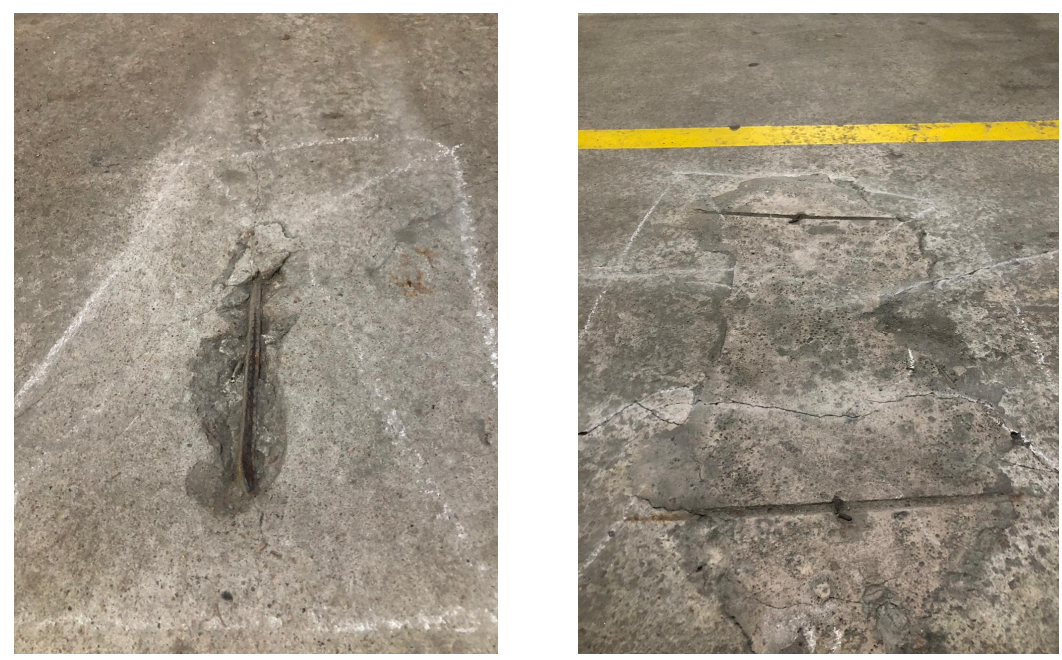

Figura 19 e 20: Armaduras expostas

\subsection{Ensaios não destrutivos}

\subsubsection{Medição da largura das fissuras}

O método utilizado para a medição da largura das fissuras sem lupa, com os equipamentos simples como a régua de fissurômetro e o paquimetro, em alguns pontos de maior visibilidade das fissuras, identificando-se fissuras, trincas e rachaduras, demostrados na figura 21 e 22 , na figura 23 os pontos coletados. 

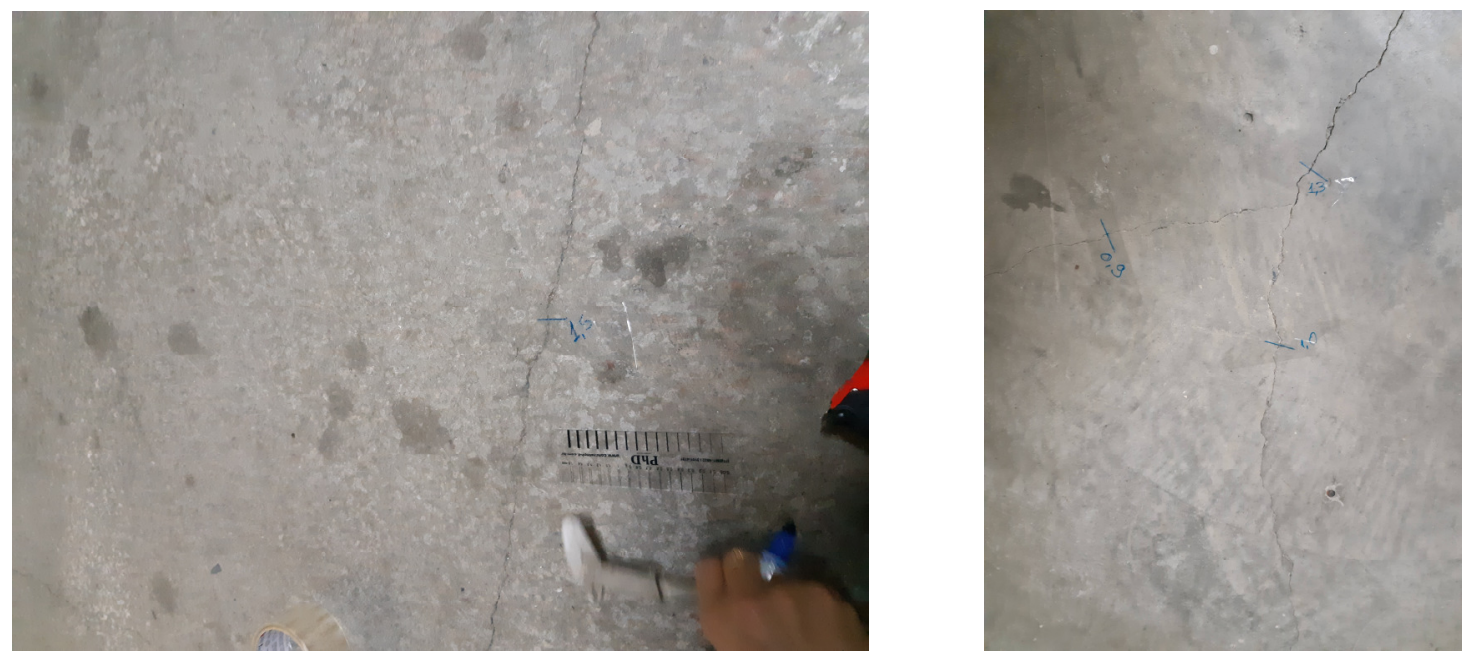

Figura 21 e 22 : Medição da largura das fissuras

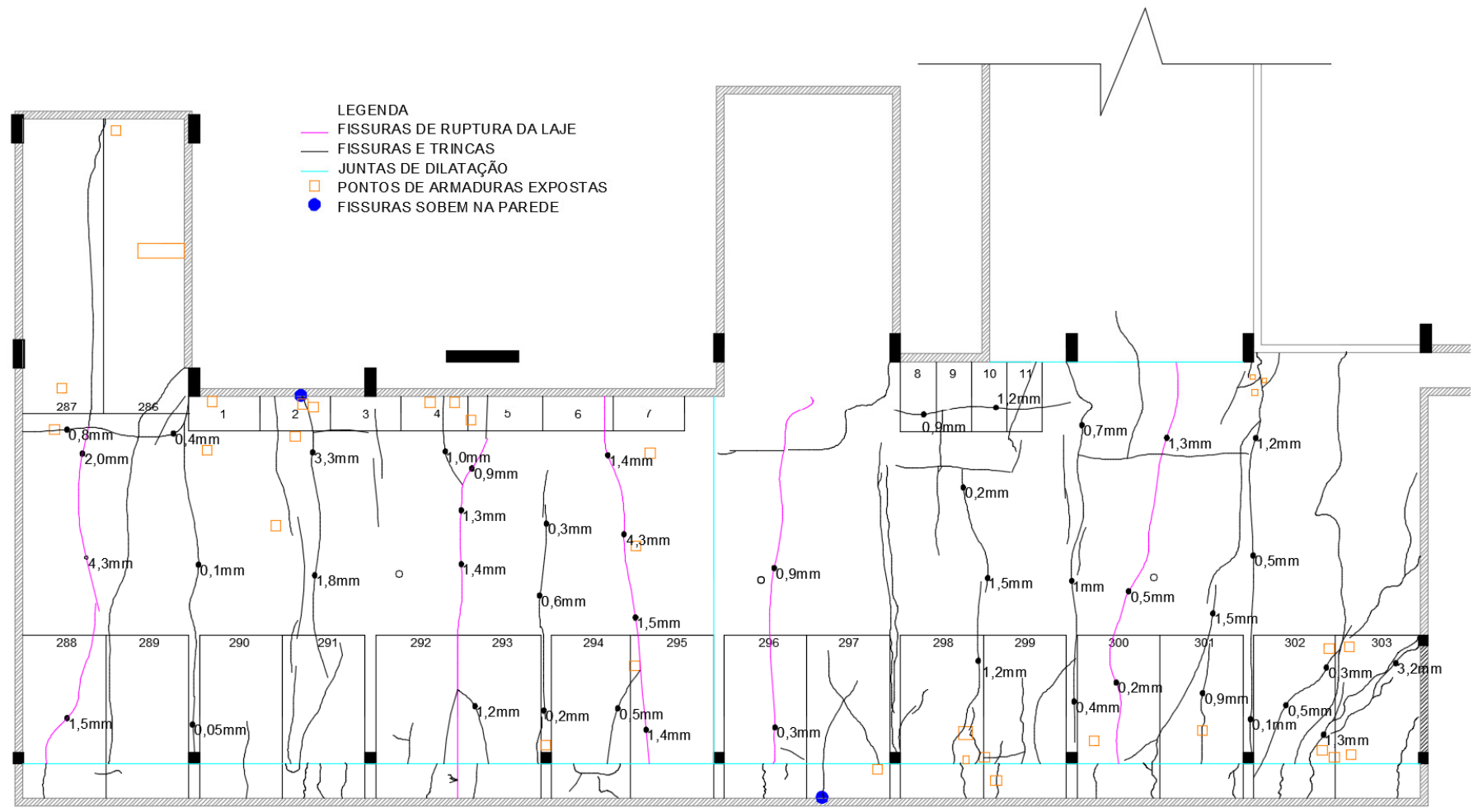

Figura 23 : Mapeamento completo das fissuras trincas e rachaduras

\subsubsection{Detector de armaduras}

Detectou-se as armaduras com o auxílio do aparelho localizador D-TECT 150 Profissional da marca Bosch, conforme figura 24, coletou-se os dados e valores aproximados das bitolas e profundidades localizadas das armaduras, com o intuído de detectar a existência de armadura positivas, negativas e a malha. 

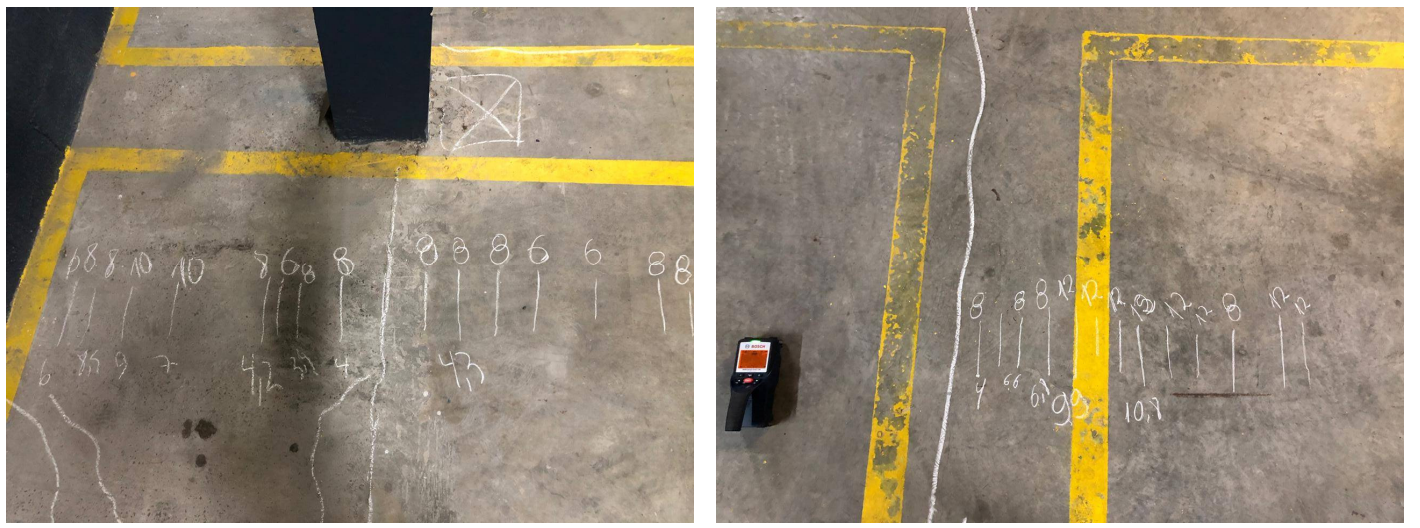

Figura 24 : Localização da armaduras

\section{ANÁLISE DE DADOS}

As trincas e fissuras que aparecem na laje de concreto sugerem ser retração hidráulica, podendo ocorrer por vários fatores, como evaporação, exsudação da água, umidade relativa do ar, velocidade do vento, temperatura do ar e do cimento, relação água x cimento (CHODOUNSKY;VIECILI,2007;OLIVEIRA;SANTOS,2016), a retração dos materiais ocorre pela perca da umidade dos materiais, podendo romper o concreto, assim surgindo as fissuras (THOMAZ,1989).

Observa-se que as fissuras generalizadas na longitudinal da laje em questão evidencia o processo de cura ineficiente e a quantidade inferior de junta de dilatação de acordo com NBR 6118 (ABNT,2014) contribuiu muito (CHODOUNSKY;VIECILI,2007), conforme pode ser observado no mapeamento das fissuras nas figuras 16 e 23 , as 5 fissuras de dilatação estão identificadas na cor magenta e estão exercendo a finalidade da junta de dilatação, originadas no local onde ocorre os esforços, pois sua função é dividir (limitar) as dimensões das placas (XEREZ NETO,2013). Na face inferior da laje essas fissuras apresentam indícios de corrosão e alguns pontos de estalactites.

Analisando individualmente cada pano de laje, observa-se que possui algumas fissuras em $45^{\circ}$ originadas do pilar e fissuras longitudinal nas bordas juntamente a viga, supõem-se que seja a falta, insuficiência, e/ou não estão no local adequado as armaduras negativas (SOUZA,2017;THOMAZ,1989), com auxílio do detector de armaduras não foi possível identificar as armaduras negativas, somente com uma análise do projeto estrutural e inspeção com ensaios para avaliar a exatidão da causa. Além disso foram detectados dois pontos de fissuras que sobem em torno de $40 \mathrm{~cm}$ na parede.

Selecionou-se algumas fissuras, trincas e rachaduras por serem mais expressivas em relação as frestas e comprimento, e com a régua de fissurômetro, coletou-se os dados e mapeaou-se, conforme figura 23 e gráfico 01,44 pontos medidos, sendo 14 pontos até $0,5 \mathrm{~mm}$ de fenda classificados como fissuras , 24 pontos de $05 \mathrm{~mm}$ até $1,5 \mathrm{~mm}$ classificados como trincas e por fim 6 pontos com mais de $1,5 \mathrm{~mm}$ de fenda classificados como rachaduras

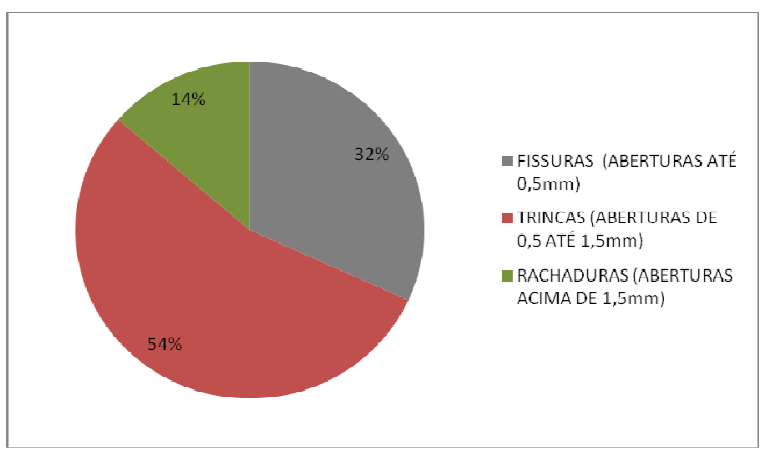

Grafico 01 : Quantitativo pontos de aberturas na laje 
$\mathrm{Na}$ face inferior da laje as armaduras de aço positivas, estão em processo de corrosão, observa-se que o cobrimento mínimo de concreto não foi atendido conforme a norma NBR6118 (ABNT,2014), que recomenda um cobrimento mínimo de $35 \mathrm{~mm}$, classe de agressividade III, conforme a sua finalidade de estacionamento e armaduras exposta na face superior da laje, nesse caso o cobrimento não existiu.

\section{CONCLUSÕES E RECOMENDAÇÕES}

Depois da vistoria realizada e das análises dos resultados, entende-se que as fissuras de retração da laje de concreto da edificação foram causadas por vários fatores originadas de falha na execução e somente com a análise do projeto podese dizer se houve falha de projeto e/ou detalhamento.

Tudo indica que conforme as configurações apresentadas, as fissuras em $45^{\circ}$ originadas no pilar e fissuras nas bordas longitudinal são fissuras de flexão da laje, recomenda-se o estudo minucioso do projeto estrutural e inspeção com ensaios para avaliar a exatidão da causa, para uma adequada reparação.

Através dos dados foi classificado fissuras devido a largura das frestas, dados de 44 pontos, sendo 16 pontos até $0,5 \mathrm{~mm}$ de fenda são fissuras e percentual de $32 \%, 24$ pontos de $05 \mathrm{~mm}$ até $1,5 \mathrm{~mm}$ são trincas e percentual de $54 \%$ e por fim 6 pontos com mais de $1,5 \mathrm{~mm}$ de fenda são rachaduras e percentual de $14 \%$, recomenda-se a inspecionar a cada 15 dias para identificar se as fissuras estão ativas ou passivas, para tratamento adequado de selagem de junta.

A falta de cobrimento mínimo das armaduras causou a aceleração do processo corrosivo e a presença de estalactite, além de pontos sem nenhum cobrimento das armaduras totalmente expostas, as fissuras também contribuíram para o desencadear deste processo.

Através dos dados percebidos, pode-se supor que o processo de carbonatação do concreto já está ocorrendo, decorrente de grandes números de fissuras existentes que permitem a entradas dos agentes agressivos e falta de cobrimento adequado. Espera-se que os profissionais da construção civil, sejam mais criteriosos, tanto quanto na elaboração de projetos e na execução, objetivando a eliminar ou minimizar as manifestações patológicas nas edificações. É importantíssimo o detalhamento e especificações num projeto, para uma boa execução.

\section{REFERÊNCIAS BIBLIOGRÁFICAS}

ASSOCIAÇÃO BRASILEIRA DE NORMAS TÉCNICAS. NBR 6118. Projeto de estruturas de concreto Procedimento. Rio de Janeiro, 2014.

Botelho, M., \& MARChetTi, O. Concreto Armado Eu Te Amo. São Paulo:, Ed. Edgar Blucher, 2004.

CAPORRINO, C. Patologias em alvenarias. São Paulo:, Ed. Oficina de Textos, 2018.

CHOdounsky, M., \& VIECILI, F. Pisos Industriais de Concreto-Aspectos Teóricos e Executivos. São Paulo, Ed.Reggenza, 2007.

MEHTA, P. K.; MONTEIRO, P. J. M. Concreto. Microestrutura, propriedades e materiais. 3. ed. São Paulo: IBRACON, 2008.

OliVeirA, J. A., \& SANTOS, M. Avaliação das Manifestações Patológicas em Pisos de Concreto Estrutural. Destinado à Circulação de Veículos em Garagem - Estudo de Caso. CBPAT2016 - Congresso Brasileiro de Patologia das Construções, -2016. Belém do Pará - CBPAT2016

SANTOS, S. Patologia das Construções. Revista Especialize On-line IPOG - Goiânia 7 edição, 2014

SOUZA, J. C. O que as rachaduras nas estruturas de concreto querem dizer?. disponível em https://www.archdaily.com.br/br/879222/o-que-as-rachaduras-nas-estruturas-de-concreto-querem-dizer

SOUZA, V. C., \& RIPPER, T. Patologia, Recuperação e Reforço de Estruturas de Concreto. Ed. Pini., 1998

THOMAZ, E. Trincas em Edificios, causas prevenção e recuperação. São Paulo: Ed. Pini, 1989 


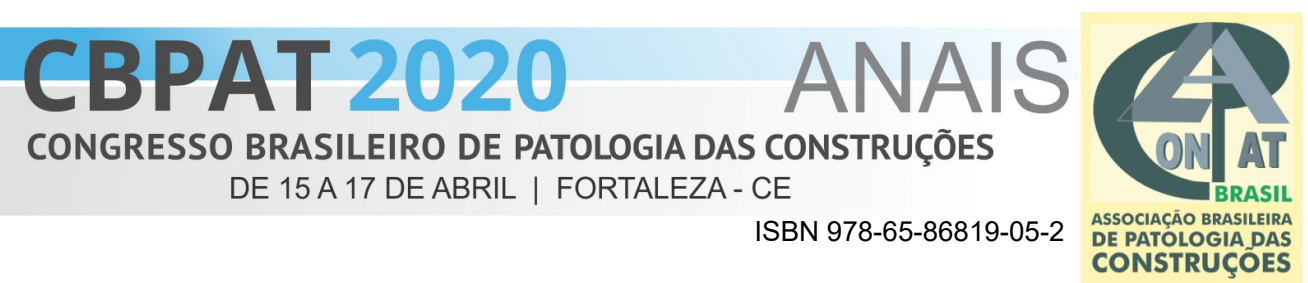

TRINDADE, D. Patologia em Estrutura de Concreto Armado. Trabalho de conclusão de Graduação em Engenharia Civil- Universidade Federal de Santa Maria, 2015

XEREZ NETO, J. Pavimentos de concreto para Tráfego de Máquinas Pesadas. Ed. PINI, 2013.

ZORZAN.L.G, OLIVEIRA L.H.M, MEDEIROS M.H.H, SOUZA, D.J. Estudo de Caso de inspeção em uma estrutura de concreto armado através de esclerometria e ultrasom - Congresso Brasileiro de Patologia das Construções, -2016. Belém do Pará - CBPAT2016 